\title{
Türkiye'de Sanayi Üretim Endeksinin Belirleyenleri: ARDL Modeli
}

\section{Determinants of Industrial Production in Turkey: ARDL Model}

\author{
Bilge PEKÇAĞLAYAN ${ }^{1}$ (
}

\begin{abstract}
Öz
Bu çalışmada sürdürülebilir bir büyüme için gerekli olan sanayi üretim endeksinin belirleyenlerinin incelenmesi amaçlanmıştır. Sanayi sektörünün toplam çıktı içindeki payı yaklaşık \%20 civarlarında olsa da gayrisafi yurtiçi hasılanın önemli bir öncül göstergesi olması açısından önemlidir. Sanayi üretim endeksi ile ilgili literatür incelendiğinde sanayi üretim endeksini etkileyen faktörlerin ve analiz yöntemlerinin birbirinden farklıık gösterdiği görülmektedir. Bu çalışmada, Türkiye ekonomisinde 2007-2020 yılları arasında aylık veriler kullanılarak ARDL (Gecikmesi Dağıtılmış Otoregresif) Modeli ile sanayi üretim endeksini etkileyen öncül göstergeler incelenmektedir. Çalışma sonuçlarına göre, elektrik tüketimi ve imalat sanayi kapasite kullanım oranı değişkenlerinin uzun dönemde sanayi üretim endeksini açıklamada anlamlı olduğu sonucuna ulaşılmıştır. Sanayi üretim endeksini açıklamada uzun dönemde en etkili olan öncül değişken ise elektrik tüketimidir. Buna göre, elektrik tüketimindeki \%1'lik artış sanayi üretim endeksini \%1.2 artıracaktır. Hata düzeltme katsayısının kısa dönem modelinde anlamlı ve negatif çıkması ise sanayi üretim endeksinde uzun dönem denge değerinden bir sapma olması halinde sistemin yaklaşık 3.5 aylık dönemde dengeye geleceğini göstermektedir.
\end{abstract}

Anahtar kelimeler: Sanayi üretim endeksi, ARDL model, Elektrik tüketimi

JEL Sınıflaması: C01, L60, O13

\begin{abstract}
In this study, it is aimed to examine the determinants of the industrial production index, which is necessary for a sustainable growth. Even though the share of the industrial sector in the total output is around $20 \%$, it is still significant as a precursor to the gross domestic product. When the literature on the industrial production index is examined, it is seen that the factors affecting the industrial production index and the analysis methods differ from each other. In this study, the leading indicators that effects the industrial production index are examined with the ARDL (Autoregressive Distributed Lag) Model using monthly data between 2007 and 2020 in the Turkish Economy. According to the results of the
\end{abstract}

DOI: 10.26650/ISTJECON2021-972114

'Dr., Türkiye Vakıflar Bankası T.A.O., Ekonomik Araştırmalar Müdürlüğü, İstanbul, Türkiye

ORCID: B.P. 0000-0002-9896-2851

Sorumlu yazar/Corresponding author: Bilge PEKÇAĞLAYAN,

Türkiye Vakıflar Bankası T.A.O., Ekonomik Araştırmalar Müdürlüğü, İstanbul, Türkiye E-posta/E-mail: bilge1017@yahoo.com

Başvuru/Submitted: 15.07.2021

Revizyon Talebi/Revision Requested:

21.11.2021

Son Revizyon/Last Revision Received:

29.11.2021

Kabul/Accepted: 29.11 .2021

Atıf/Citation: Pekçaglayan, B. (2021). Türkiye'de sanayi üretim endeksinin belirleyenleri: ARDL modeli. Istanbul iktisat Dergisi - Istanbul Journal of Economics, 71(2), 435-456. https://doi.org/10.26650/ISTJECON2021-972114 
study, it was concluded that the variables of electricity consumption and manufacturing industry capacity utilization rate are significant in explaining the industrial production index in the long run. The leading variable that is most effective in explaining the industrial production index in the long run is electricity consumption. Accordingly, $1 \%$ increase in electricity consumption will increase the industrial production index by $1.2 \%$. The fact that the error correction coefficient is significant and negative in the short- term model indicates that if there is a deviation from the long-term equilibrium value in the industrial production index, the system will reach equilibrium in approximately 3.5 months.

Keywords: Industrial production index, ARDL model, Electricity consumption

JEL Classification: C01, L60, O13

\section{EXTENDED ABSTRACT}

In this study, it is aimed to examine the determinants of the industrial production index, which is necessary for sustainable growth. Even though the share of the industrial sector in the total output is around $20 \%$, it is still significant as a precursor to the gross domestic product. The industrial production affects the economy in many ways. The increase in industrial production through both domestic consumption and exports is closely related to economic growth. The fact that industrial production is sensitive to both consumption demand and interest rates makes the industrial production index closely related to growth. The importance of the manufacturing industry sector, which has a weight of more than $80 \%$ in the industrial production index, is enormous. One of the first studies which reveal the impact of the manufacturing industry sector on economic growth is Kaldor's 1966 study. The first rule accepted as Kaldor's laws of growth reveals that the manufacturing industry is the main factor of economic growth. The increase in the share of the manufacturing industry sector, which has a high multiplier effect, will also increase the growth.

When the literature on the industrial production index is examined, it is seen that the factors affecting the industrial production index and the analysis methods differ from each other. In this study, the relationship between the leading indicators of the industrial production index, which is one of the most important leading indicators of economic growth, is examined with the ARDL (Autoregressive Distributed Lag) Model using monthly data between 2007 and 2020 in the Turkish Economy. In this model, electricity consumption, white goods production and manufacturing industry capacity utilization rate are used as independent variables to explain the industrial production index. 
According to the results of the study, electricity consumption and manufacturing industry capacity utilization rate are significant in explaining the industrial production index in the long run. The leading variable which is most effective in explaining the industrial production index is the electricity consumption. According to the results, $1 \%$ increase in electricity consumption increases the industrial production index by $1.2 \%$. In addition, 1 -unit change in the capacity utilization rate increases the industrial production index by $0.5 \%$. On the other hand, in the short run, it is concluded that $1 \%$ increase in electricity consumption will increase the industrial production index by $0.6 \%$. Also, $1 \%$ increase in white goods production will increase the industrial production index by $0.3 \%$ and 1 - unit change in the capacity utilization rate increases the industrial production index by $0.6 \%$. Since the error correction coefficient is significant and negative in the short-term model indicates that the system will return to equilibrium if there is a deviation from the long-term equilibrium. Accordingly, the error correction coefficient being -0.28 indicates that if there is a deviation from the long-term balance in the industrial production index due to a shortterm shock, the system will stabilize in approximately 3.5 months. In other words, it shows that $28.2 \%$ of the deviation that will occur in the long-term balance due to a shock in the short-term might be eliminated at the end of the 1-month period. Effect of white goods production, which had an impact on the industrial production index in the short term, disappeared in the long term. Furthermore, the effect of capacity utilization rate is very limited in both the long and short run.

In future studies, the relationship of industrial production index with leading indicators such as exports, imports of intermediate goods and capital goods, manufacturing industry purchasing managers index (manufacturing PMI), automobile production can be analyzed. 


\section{Giriş}

Sanayi sektörünün toplam çıktı içindeki payı yaklaşı \%20 civarlarında olsa da gayrisafi yurtiçi hasılanın önemli bir öncül göstergesi olması açısından önemlidir. Bunun temel nedeni sanayi üretiminin ekonomiyi pek çok açıdan etkilemesidir. Gerek yurtiçi tüketim gerekse ihracat yoluyla sanayi üretimindeki artış ekonomik büyüme ile yakından ilişkilidir. Sanayi üretiminin hem tüketim talebine hem de faiz oranlarına duyarlı olması sanayi üretim endeksini büyüme ile yakından ilişkili kılmaktadır. Özellikle sanayi üretim endeksi içinde ağırlığı \%80'nin üzerinde olan imalat sanayi sektörünün önemi büyüktür. İmalat sanayi sektörünün ekonomik büyüme üzerindeki etkisini ortaya koyan ilk çalısmalardan biri Kaldor'un 1966 yılındaki çalışmasıdır. Kaldor'un büyüme yasaları olarak kabul edilen yasalardan ilki, imalat sanayinin ekonomik büyümenin lokomotifi olduğunu ortaya koymaktadır. Çarpan etkisi yüksek olan imalat sanayi sektörünün gayrisafi yurtiçi hasıladaki payının yükselmesi üretimi dolayısıyla büyümeyi artıracaktır.

Sanayi üretim endeksi, Türkiye İstatistik Kurumu (TÜiK) tarafından aylık olarak açıklanmaktadır ve ekonominin sanayi tarafında meydana gelen gelişmelerin ve uygulanan ekonomik politikaların, kısa dönemde olumlu veya olumsuz etkilerinin ölçülmesi için hesaplanmaktadır. Sanayi üretim endeksi hesaplanırken; imalat, madencilik ve taş ocakçılığı ile elektrik, gaz, buhar ve iklimlendirme üretimi ve dağııımı sektörleri kapsanmakta ve söz konusu sektörlerdeki reel büyüme baz yılına göre ölçülmektedir. Sanayi üretim endeksi hesabında kullanılan veriler, aylık sanayi üretim soru kağıdından elde edilen verilerden ve anket kapsamında olmayan işyerleri için ise Gelir İdaresi Başkanlığı verilerinden hesaplanan ciro bilgilerinden oluşmaktadır. Sanayi üretim endeksi, her ay arındııılmamış, takvim etkisinden arındırılmış, mevsim ve takvim etkisinden arındırılmış olarak açıklanmaktadır. Arındırılmamış sanayi üretim endeksi verisinden takvim ve tatilden (hafta sonu tatili, resmî tatil ve bayram tatili) kaynaklanan etkiler arındırıldığında takvim etkisinden arındırılmış veriler elde edilmektedir. Hem arındırılmamış hem de takvim etkisinden arındırılmış veriler, geçen yılın aynı ayına göre yapılan kıyaslamalarda kullanılmaktadır ve yıllık değişimi göstermektedir. Takvim etkisinin yanı sıra sanayi üretim endeksinde o ayı etkileyebilecek geçici nitelikte etkilerin 
varlığı göz önüne alındığında, bu etkiler mevsimsel etkiler (hava koşulları, grevler, elektrik kesintisi, makine arızaları, çalışma saatlerindeki aksamalar, makine ve tesisatın bakım araları gibi geçici nedenlerden dolayı ortaya çıkan farklılılar) olarak adlandırılmaktadır. Arındırılmamış veriden hem takvim hem de mevsimsel etkilerden kaynaklanan hareketler arındırıldığında mevsim ve takvim etkilerinden arındırılmış sanayi üretim endeksi verisi elde edilmektedir. Mevsim etkilerinden arındırılmış veriler, bir önceki aya göre yapılan kıyaslamalarda kullanılmaktadır ve aylık değişimi ifade etmektedir (Eğilmez, 2014). Sanayi üretim endeksi büyümenin en önemli öncül göstergelerinden biri olduğundan dolayı yakından takip edilmektedir. Çalışmada 2007-2020 yılları arasında çeyrek dönemlik veriler kullanılarak sanayi üretim endeksi ve büyüme arasındaki korelasyon \%95 olarak hesaplanmıştır. Buna göre, sanayi üretim endeksi verileri bir sonraki çeyrekte açıklanacak büyüme rakamları hakkında önemli bir öngörü sağlamaktadır. Bu çalışmada sürdürülebilir bir büyüme için gerekli olan sanayi üretim endeksinin belirleyenlerinin incelenmesi amaçlanmıştır. Sanayi üretim endeksini tahmin etmek kısa dönemli ekonomik analizde önemlidir (Bruno ve Lupi, 2003).

Sanayi üretim endeksi ile ilgili literatür incelendiğinde, sanayi üretim endeksini etkileyen faktörlerin ve analiz yöntemlerinin birbirinden farklılaştığı görülmektedir. Literatürdeki çalışmalarda sanayi üretim endeksini açıklamak üzere ithalat, ihracat, işgücü anketlerine dayalı veriler vb. değişkenlerin kullanıldığı ve bu amaçla VAR (Vektör Otoregresyon Modeli) analizinin ilgili literatürde öne çıkan yöntem olduğu görülmektedir. Az sayıdaki çalışmada ise elektrik tüketimine yer verildiği ve ARDL (Gecikmesi Dağıtılmış Otoregresif) Modeli kullanıldığı görülmektedir. Bu çalışmada ise, sanayi üretim endeksini açıklamak üzere literatürdeki çalışmalardan farklı olarak elektrik tüketiminin yanı sıra beyaz eşya üretimi ve imalat sanayi kapasite kullanım oranı değişkenleri ele kullanılarak sanayi üretim endeksinin açıklanması amaçlanmıştır. Ayrıca çalışmada literatürde yaygın olarak kullanılan yöntemlerden farklı olarak ARDL Modeli kullanılmaktadır. Bu amaca yönelik olarak, Türkiye ekonomisinde 2007-2020 yıllarını kapsayan aylık veriler kullanılarak sanayi üretim endeksini açıklayan öncül göstergeler incelenmektedir. Çalışmada, elektrik tüketimi ve imalat sanayi kapasite kullanım oranı değişkenlerinin uzun dönemde sanayi üretim endeksini açıklamada anlamlı olduğu bulgulanmaktadır. Ayrıca 
çalışmanın bir diğer önemli bulgusu ise, sanayi üretim endeksinde uzun dönem denge değerinden bir sapma olması halinde sistemin yaklaşık 3.5 aylık dönemde dengeye geleceğini göstermesidir. Sonuç olarak, makalenin literatüre katkısı Türkiye'de sanayi üretim endeksini tahmin etmek üzere elektrik tüketimi, beyaz eşya üretimi ve kapasite kullanım oranı değişkenlerinin birlikte ele alınarak sanayi üretim endeksinin öncül değişkenlerle ilişkisinin ARDL Modeli kullanılarak açıklanmasıdır.

Makalenin bölümleri şu şekilde organize edilmiştir: 2.Bölüm sanayi üretim endeksi ile ilgili ulusal ve uluslararası literatürün incelendiği bölümdür. 3.Bölüm çalışmada kullanılan veri setini ve ekonometrik yöntemi kapsamaktadır. 4.Bölüm Türkiye'de sanayi üretim endeksinin belirleyenlerini irdelemeye yönelik ampirik analizi içermektedir. Sonuç bölümünde ise elde edilen bulgular değerlendirilmektedir.

\section{Literatür Taraması}

Sanayi üretim endeksini temel alan ulusal çalışma sayısı oldukça önemli düzeydedir. Türkiye için sanayi üretim endeksinin belirleyenlerinin araştırıldığı çalışmalardan bazıları aşağıda yer almaktadır:

Erkişi ve Tekin (2019), 2010-2017 yılları arasında üçer aylık verileri kullanarak sanayi üretimi, ara malı ithalatı, sermaye malı ithalatı ve ekonomik büyüme arasındaki ilişkiyi incelemişlerdir. Çalışmada, değişkenler arasındaki kısa dönemli ilişkinin nedeni VAR Granger Nedensellik Analizi ile uzun dönemli ilişkinin nedeni ise Johansen Eşbütünleşme Testi ile araştırılmıştır. Çalışma sonucuna göre, kısa dönemde sanayi üretimi ile ara malı ithalatı arasında iki yönlü nedensellik, sanayi üretiminden ekonomik büyümeye tek yönlü nedensellik tespit edilirken, sanayi üretimi ile sermaye malı ithalatı arasında kısa dönemde herhangi bir nedensellik tespit edilmemiştir. Uzun dönemde ise söz konusu değişkenler arasında ilişki olduğu sonucuna varılmıştır.

Öncel Çekim (2018), 2005-2017 yılları arasındaki aylık sanayi üretim endeksi verilerini kullanarak Türkiye'de sanayi üretim endeksini zaman serileri yöntemi ile 
incelemiştir. Çalışmanın amacı sanayi üretim endeksi serisine uygun zaman serisi modelini bularak endeksin gelecek değerlerini tahmin etmektir. Seriye en uygun model olarak SARIMA $(1,1,1)(3,2,0)$ modeli belirlenmiştir. Elde edilen model kullanılarak sanayi üretim endeksi serisinin 2018 yılı için aylık öngörü değerleri elde edilmiştir.

Öztürk ve Agan (2017), Türkiye ekonomisi için 2002-2012 yıllarına ait çeyrek dönemlik verileri kullanarak yaptıkları çalışmalarında sanayi üretim endeksinin belirleyenlerini VAR yöntemi ile incelemişlerdir. Bu amaçla çalışmada, sanayi üretim endeksi bağımlı değişken; ihracat, yatırımlar ve faiz oranları ise bağımsız değişkenler olarak alınmıştır. Çalışma sonucunda, bağımsız değişkenlerin tamamı sanayi üretim endeksini açıklamada anlamlı bulunmuştur.

Bayar ve Tokpunar (2014), Türkiye için sanayi üretiminin büyümenin ana itici gücü olduğundan hareketle, Türkiye Ekonomisi için büyük önem taşıyan imalat sanayi üretiminin belirleyenlerini analiz etmişlerdir. Bu amaçla, 2005 yılı ilk çeyrek ve 2011 yılı ilk çeyrek arasını kapsayacak şekilde 78 sektörü içeren panel veri seti kullanılarak Genişletilmiş Ortalama Grup (AMG) yöntemi ile analiz yapılmıştır. Çalışma sonucuna göre, sektörel ihracat ve ithalat, toplam yatırımlar, sektörel verimlilik ve ticaret ortaklarının gayrisafi yurtiçi hasılasının imalat sanayi sektörlerinin üretimini pozitif yönde etkilediği bulunmuştur. Çalışmanın bir diğer bulgusu ise reel kurun değer kazanmasının ve faiz oranlarındaki artışın imalat sanayi sektörü üretimini düşürdüğü tespitidir.

Öcal (2013), 2001-2008 dönemi için aylık verileri kullanarak imalat sanayi eğilim anketinde yer alan 15 gösterge ile sanayi üretim endeksi arasındaki uzun dönemli ilişkiyi Engle-Granger analizinin yanı sıra Johansen Eşbütünleşme analizi ile araştırmıştır. Uzun dönemli ilişkiye sahip olduğu tespit edilen değişkenler için ise hata düzeltme modeli ile denge durumuna ulaşılmasına kadar kısa dönemdeki sapmaların ne kadarının düzeltildiği tespit edilmiştir. Sanayi üretim endeksi üzerinde üretim miktarının pozitif etkisi bulunduğu ve üretim miktarındaki \%1'lik artışın sanayi üretim endeksini \%12.13 artırdığı tespit edilmiştir. 
Barışık ve Yayar (2012), Türkiye ekonomisi için Ocak 1998-Aralık 2010 dönemi aylık verilerini kullanarak sanayi üretim endeksini etkileyen iktisadi değişkenleri araştırmışlardır. Çalışmada sanayi üretim endeksini etkileyen değişkenleri belirlemek üzere regresyon analizi, etki-tepki ilişkilerini belirlemek ve sanayi üretimini en fazla etkileyen değişkenleri tespit etmek üzere ise VAR (Vektör Otoregresyon Modeli) analizi kullanılmıştır. Regresyon analizi sonucuna göre, petrol fiyatları, döviz kuru, ihracat gibi dışsal değişkenlerin; kamu harcaması, tüketim harcaması, ithalat gibi içsel değişkenlerin sanayi üretimini etkilediği tespit edilmiştir. VAR analizine göre ise, sanayi üretimini en fazla ithalat ve kamu harcamalarının etkilediği bulunmuştur.

Kızılca (2007), Türkiye'de sanayi üretim endeksini etkileyen faktörleri 1980-2001 dönemi için yıllık verileri kullanarak zaman serisi analizi ile incelemiştir. Çalışmada, sanayi üretim endeksini etkileyen faktörleri belirlemek üzere sanayi ürünleri ihracatı, sanayi ürünleri ithalatı, işyeri sayısı, istihdam, reel katma değer ve reel ücret bağımsız değişkenleri kullanılmıştır. Çalışma sonucuna göre, istihdam, reel katma değer ve sanayi ürünleri ihracatı sanayi üretim endeksini açılamada anlamlı bulunmuştur.

Sanayi üretim endeksinin belirleyenlerinin araştııldı ı̆ı uluslararası çalışmalardan bazıları ise aşağıda yer almaktadır:

Ejaz ve lqbal (2019), Pakistan için aylık sanayi üretim endeksinin tahmin edilmesini amaçlamışlardır. Pakistan'da sanayi üretim endeksi tahminleri aylık olarak bulunmamaktadır. Ekonomik aktiviteyi ölçmek üzere kullanılan büyük ölçekli imalat (LSM) verisi yerine kullanılmak üzere aylık sanayi üretim endeksi tahminlerinin elde edilmesi amaciyla ARIMA, ARDL, VAR ve Bayesyen VAR modelleri ile çalışılmıştır. Bu amaçla Temmuz 1990-Haziran 2018 dönemi verileri kullanılarak sanayi üretim endeksindeki yıllık değişimleri tahmin etmek üzere reel, finansal ve dış sektörlerdeki koşulları yansıtan farklı ekonometrik modeller kullanılmıştır. Çalışmada mal ihracatı, ithalatı, emtia fiyatları, ABD sanayi üretim endeksi, elektrik tüketimi, şirketlerin yaptığı sermaye harcamaları, sanayiye sunulan finansmana ilişkin veriler gibi geniş bir veri seti kullanılmıştır. Sonuçlar, finansal koşulları yansıtan ARDL modelinin tercih edildiğini göstermektedir. 
Bruno ve Lupi (2003), İtalya için sanayi üretim endeksinin tahmin edilmesine yönelik model geliştirmişlerdir. Çalışmada 1988-1998 yılları arasında çeyrek dönemlik verilerle çalışılarak ARIMA ve VAR modelleri kullanılmıştır. Bu amaçla gelecekteki üretim beklentilerine ilişkin iş anketleri serisi ve demiryolları ile taşınan mal miktarı bağımsız değişken olarak kullanılmıştır. VAR modelinin ARIMA modeline kıyasla daha iyi sonuçürettiği gözlemlenmiştir. Ayrıca çalışma sonucunda oluşturulan modelin İtalya'da sanayi üretim endeksinin tahmininde daha uzun vadeli güvenilir tahminler ürettiği sonucuna varılmıştır.

Bruno ve Lupi (2003), Euro Bölgesi'nde sanayi üretim endeksini tahmin etmek için Almanya, Fransa ve İtalya'dan elde edilen sanayi üretim endeksi tahminlerini kullanmışlardır. Almanya ve Fransa'da, iktisadi eğilim anketlerinden elde edilen ve dinamik faktör modeli ile tek değişkene indirilen veriler kullanılarak sanayi üretim endeksi tahmini için VAR modeli kullanılmıştır. Elde edilen tahminlerin Fransa için 6 ay ileriden ve Almanya için ise 3 ay ileriden güvenilir sonuçlar verdikleri tespit edilmiştir. İtalya'da sanayi üretim endeksinin tahmini için farklı bir yaklaşım olarak üç değişkenli VAR modeli yaklaşımı kullanılmıştır. İtalya için sanayi üretim endeksinin tahmininde Fransa ve Almanya'dan farklı olarak tren yolu ile taşınan malların ton biriminde miktarları kullanılmışır.

Parigi, Golinelli ve Bodo (2000), Euro Bölgesi'nde ve Euro Bölgesi'nin dört büyük ekonomisi olan Almanya, Fransa, İtalya ve İspanya'da sanayi üretimini tahmin etmek üzere tek değişkenli ARIMA modellerinden ve VAR modellerinden yararlanmışlardır. Çalışmada 1987-1997 yıllarını kapsayacak aylık veri seti kullanılarak modelleme yapılmıştır. 1998 yılı Ocak ayı ve 1996 yılı Haziran ayı verileri ise tahmin performansını değerlendirmek üzere kullanılmıştır. Çalışma sonucuna göre ARIMA modellerinin sanayi üretim endeksi tahmini için ülke bazında ve Euro Bölgesi'nin tamamı için kısa dönemli (1-2 aylık) tahminlerde yeterli olduğu sonucuna ulaşılmışır. VAR modellerinin ise aşırı parametrelendirme nedeniyle yeterli olmadığı sonucuna varılmıştır.

Marchetti ve Parigi (1998), İtalya'da sanayi üretim endeksini elektrik tüketimine dayalı olarak kurulan model ile Mayıs 1995 ve Eylül 1997 dönemine ait aylık 
verileri kullanarak araştırmışlardır. Elektrik tüketiminin yanı sıra farklı işgücü anketlerine dayalı veriler kullanılmıştır. Çalışmada elde edilen bulgulara göre, sanayi üretimi ile elektrik tüketimi arasında yakın ilişki bulunmaktadır. Sanayi üretimine ilişkin en iyi performans ise hem enerji tüketimine hem de anket verilerine dayalı olan birleştirilmiş model sonucunda elde edilmiştir.

\section{Veri Seti ve Ekonometrik Yöntem}

Çalışmanın bu bölümünde ekonomik büyümenin en önemli öncül göstergelerinden biri olan sanayi üretim endeksinin belirleyenleri 2007-20201 yılları arasındaki aylık veriler kullanılarak incelenmektedir. Bu amaçla aşağıda yer alan regresyon modeli (1) tanımlanmıştır.

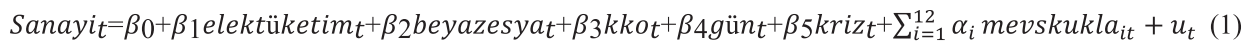

Modelde, sanayi üretim endeksini açıklamak üzere elektrik tüketimi, beyaz eşya üretimi ve imalat sanayi kapasite kullanım oranı bağımsız değişkenler olarak modele eklenmiştir. Sanayi üretim endeksi (sanayi), TÜiK'ten alınmıştır ve arındırılmamış sanayi üretim endeksi serisi ile çalışılmıştır. Elektrik tüketiminin imalat sanayinde önemli bir yeri olduğundan dolayı elektrik tüketimi sanayi üretim endeksi ile yakından ilişkilidir. Elektrik tüketimi (elektüketim), TEIAŞ'tan alınmıştır. Beyaz eşya üretimi (beyazeşya) Hazine ve Maliye Bakanlığı'ndan alınmış olup beyaz eşya üretimindeki artış sanayi üretim endeksindeki artışı desteklemektedir. Modeldeki bir diğer değişken imalat sanayi kapasite kullanım oranıdır. İmalat sanayi kapasite kullanım oranı, imalat sanayinde faaliyet gösteren iş yerlerinin mevcut fiziki kapasitelerine göre fiilen gerçekleşen kapasite kullanımlarıdır. Türkiye'nin uzun yıllar ortalamasına bakıldığında bu oranın \%80 civarında olması gerektiği görülmektedir. Kapasite kullanım oranındaki artış sanayi üretim endeksine artış olarak yansımaktadır. İmalat sanayi kapasite kullanım oranı ( $k$ ko) değişkeni TCMB'den alınmıştır. Sanayi üretim endeksinin öncül verileri, sanayi

1 İmalat sanayi kapasite kullanım oranı (kko) değişkeni 2007 yılının Ocak ayından başladığı için modellemede 2007 yılından itibaren aylık veri seti kullanılmıştır. 
üretim endeksi açıklanmadan önce sanayi üretim endeksinin seyrine ilişkin fikir vermesi bakımından değerlendirilmektedir. Modelde imalat sanayi kapasite kullanım oranı (kko) dışında tüm değişkenlerin logaritmik dönüşümleri kullanılmıştır.

Mevsim ve takvimden kaynaklanan etkiler, geçici nitelikte olduklarından verinin genel eğiliminin gözlenmesine engel olmaması için modelde takvimden kaynaklanan etkileri kontrol etmek üzere değişken tanımlaması (gün) yapılmışır. Seri, 1974-2015 yılları arasında mevcut olup, TCMB'den alınmıştır (Atabek vd., 2009). 2015-2020 yılları için ise aylık olarak uzatılmışıır². Modelde mevsimsel etkiyi kontrol etmek üzere mevsimsel kukla değişken (mevskukla) tanımlaması yapılmıştır. Sanayi üretim endeksinde sert hareketlerin yaşandığını ayları kontrol etmek üzere değişken (kriz) tanımlaması yapılmıştır.

\section{Şekil 1: Değişkenlerin Zaman Serisi Grafikleri}
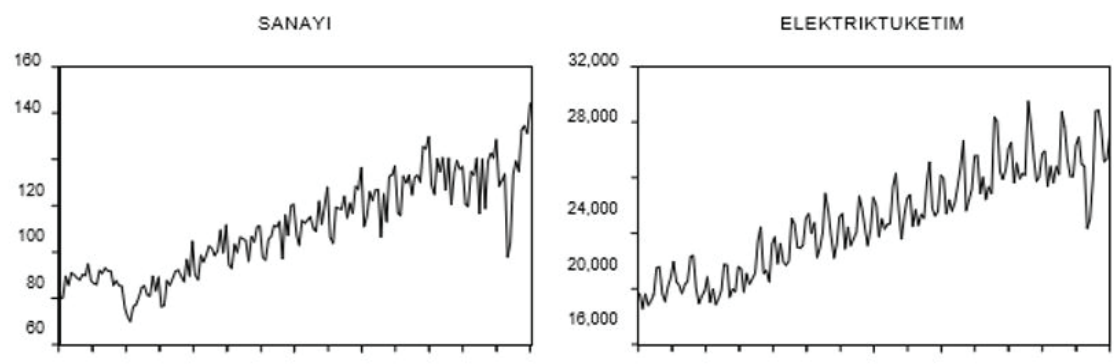

40

$\begin{array}{lllllll}2008 & 2010 & 2012 & 2014 & 2016 & 2018 & 2020\end{array}$

12,000

$\begin{array}{lllllll}2008 & 2010 & 2012 & 2014 & 2016 & 2018 & 2020\end{array}$

BEYAZESYA
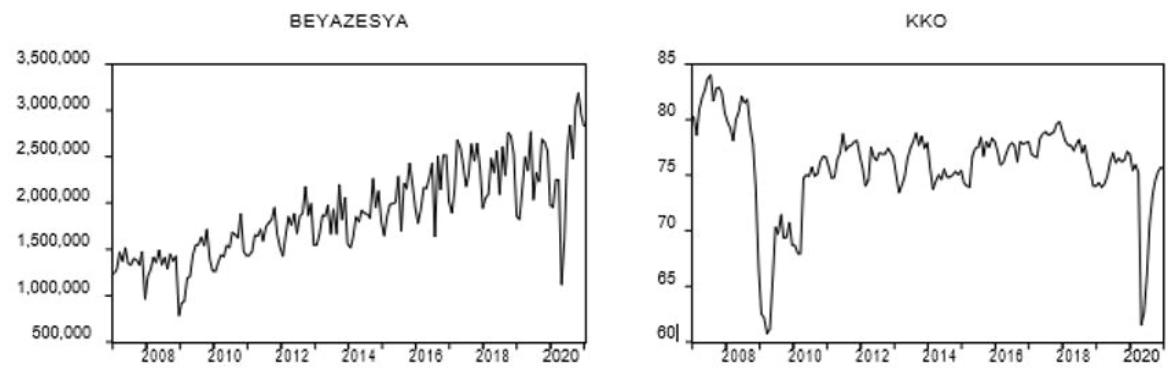

2 Serinin uzatılmasında Atabek vd. (2009) makalesindeki hesaplamalardan yararlanılmıştır. 
Değişkenlere ilişkin tanımlayııı istatistikler Tablo 1'de özetlendiği gibidir:

Tablo 1. Değişkenlerin Tanımlayıcı İstatistikleri

\begin{tabular}{|l|c|c|c|c|}
\hline & Sanayi & Elektrik Tüketimi & Beyaz Eşya Üretimi & Kapasite Kullanım Oranı \\
\hline Ortalama & 90.96 & 20969.57 & 1895436 & 75.97 \\
\hline Medyan & 90.93 & 21056.27 & 1868265 & 76.75 \\
\hline Maksimum & 144.78 & 29556.09 & 3203107 & 84.10 \\
\hline Minimum & 50.45 & 14547.95 & 790006 & 60.80 \\
\hline Standart Sapma & 20.76 & 3749.7 & 474944.5 & 4.20 \\
\hline Çarpıklık & 0.19 & 0.15 & 0.33 & -1.51 \\
\hline Basıklık & 2.11 & 2.13 & 2.58 & 6.24 \\
\hline Toplam & $\mathbf{1 6 8}$ & $\mathbf{1 6 8}$ & $\mathbf{1 6 8}$ & $\mathbf{1 6 8}$ \\
\hline
\end{tabular}

Tanımlayıcı istatistiklerin yer aldığı Tablo 1'e göre, 2007-2020 yılı aylık sanayi üretim endeksi verileri değerlendirildiğinde, arındırılmamış verilerle sanayi üretim endeksinin ortalaması 90.96 iken; minimum değeri 50.45 ve maksimum değeri 144.78'dir. Elektrik tüketimi aynı dönemde ortalama olarak 20,969.57 gigawatt saat olarak gerçekleşmiştir. Elektrik tüketiminin maksimum olduğu ayda tüketilen elektrik miktarı 29,556.09 gigawatt saat iken; minimum olduğu ayda tüketilen elektrik miktarı 14,547.95 gigawatt saattir. Beyaz eşya üretimi 2007-2020 döneminde aylık ortalama 1 milyon 895 bin adettir. Söz konusu dönemde üretilen maksimum beyaz eşya miktarı aylık 3 milyon 203 bin adet iken; minimum üretim miktarı ise 790 bin adet olarak gerçekleşmiştir. Kapasite kullanım oranı çalışmanın yapıldığı 14 yıllık dönemde aylık \%75.97 olarak gerçekleşmiştir. Kapasite kullanım oranı söz konusu dönemde maksimum \%84.1 iken; minimum \%60.8 olarak gerçekleşmiştir. Kapasite kullanım oranı değişkeni sola çarpık bir dağılıma sahip iken; diğer değişkenlerin dağııımının sağa çarpık olduğu görülmektedir. Sanayi üretim endeksi, elektrik tüketimi ve beyaz eşya üretimi değişkenleri normal dağılımdan önemli ölçüde sapma göstermezken; kapasite kullanım oranı değişkeninin normal dağılımdan sapma gösterdiği tespit edilmiştir. Değişkenlerin tamamı normal dağılıma göre daha sivri dağılıma sahiptir.

Engle-Granger (1987) ve Johansen (1988) eş bütünleşme testleri sıklıkla değişkenler arasındaki uzun dönemli ilişkilerin incelenmesinde kullanılmaktadır ve bu testler değişkenlerin aynı mertebeden durağan olmasını gerektirmektedir. 
Pesaran, Shin ve Smith (2001) tarafından geliştirilen Gecikmesi Dağıtılmış Otoregresif Sınır Testi (ARDL - Auto Regressive Distributed Lag) yaklaşımı ise farklı mertebeden durağan değişkenler arasında eş bütünleşme ilişkisinin incelenmesine olanak sağlar. Çalışmada, değişkenler arasında uzun dönemli bir ilişkinin var olup olmadığını araştırmak için kısıtlanmamış hata düzeltme modeli (2) nolu denklemde ortaya konulmuştur.

$\Delta$ lnsanayi $_{t}=\beta_{0}+\beta_{1}$ lnsanayi $_{t-1}+\beta_{2}$ lnelektüketim $_{t-1}+\beta_{3}$ lnbeyazesya $_{t-1}+\beta_{4}$ kko $_{t-1}+\beta_{5}$ gün $_{t}+$

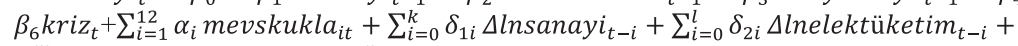
$\sum_{i=0}^{m} \delta_{3 i}$ Llnbeyazesya ln $_{t-i}+\sum_{i=0}^{n} \delta_{4 i} \Delta k k o_{t-i}+u_{\mathrm{t}}$

(2) nolu eşitlikte $\Delta$ fark operatörünü ve $u_{\mathrm{t}}$ ise hata terimini ifade etmektedir. Değişkenler arasında uzun dönemli ilişkinin olup olmadığını test etmek üzere boş ve alternatif hipotez aşağıda tanımlanmıştır:

Ho: $\beta_{1}=\beta_{2}=\beta_{3}=\beta_{4}=0$

$\mathrm{H}_{1}: \beta_{1} \neq \beta_{2} \neq \beta_{3} \neq \beta_{4} \neq 0$

ARDL uzun dönem formu ve sınır testi ile hesaplanan F-test istatistiği Pesaran, Shin ve Smith (2001) tarafından asimptotik olarak türetilen anlamlılık düzeyleri ile karşılaştııılmaktadır. F-test istatistiğinin Pesaran, Shin ve Smith (2001) tarafından asimptotik olarak türetilen kritik değerlerin üst sınırından büyük olması durumunda boş hipotez reddedilecektir. Bu durum değişkenler arasında uzun dönem ilişkisi olduğuna işaret etmektedir. Sınır testi ile değişkenler arasında uzun dönemli ilişkinin tespit edilmesi halinde uzun dönem katsayıları tahmin edilecektir.

Çalışmada, uzun dönem katsayılarını tahmin etmek üzere (3) nolu eşitlikte yer alan ARDL $(k, l, m, n)$ modeli oluşturulmuştur. Model, (3) nolu denklemde verildiği gibidir:

$$
\begin{aligned}
& \text { lnsanayi }_{t}=\beta_{0}+\beta_{1} \text { gün }_{t}+\beta_{2} \text { kriz }_{t}+\sum_{i=1}^{12} \alpha_{i} \text { mevskukla } i t+\sum_{i=1}^{k} \delta_{1 i} \text { lnsanayi }_{t-i}+ \\
& \sum_{i=0}^{l} \delta_{2 i} \text { lnelektüketim }_{t-i}+\sum_{i=0}^{m} \delta_{3 i} \text { lnbeyazesya }_{t-i}+\sum_{i=0}^{n} \delta_{4 i} k k o_{t-i}+u_{\mathrm{t}}
\end{aligned}
$$


Uzun dönemli ilişkiye ait katsayılar belirlendikten sonra otokorelasyon, değişen varyans olup olmadığı incelenmiş ve model parametrelerinin kararlılığı için CUSUM ve CUSUMQ testleri gerçekleştirilmiştir.

Çalışmada, değişkenler arasındaki kısa dönemli ilişkilerin belirlenmesi amacıyla ARDL modele dayalı (4) nolu denklemdeki hata düzeltme modeli tahmin edilmektedir.

$$
\begin{aligned}
& \text { Alnsanayi } t_{t}=\beta_{0}+\beta_{1} \text { gü }_{t}+\beta_{2} \text { kriz }_{t}+\sum_{i=1}^{12} \alpha_{i} \text { mevskukla }_{i t}+\sum_{i=1}^{k} \delta_{1 i} \Delta \text { lnsanayi }_{t-i}+ \\
& \sum_{i=0}^{l} \delta_{2 i} \text { Llnelektüketim } \\
& t-i
\end{aligned}
$$

$E C M_{t-1}$ hata düzeltme terimi olup; bu terimin katsayısı olan $\delta_{5}$ kısa dönemde meydana gelen bir dengesizliğin ne kadarının uzun dönemde düzeleceğini göstermektedir. $\delta_{5}$ 'in negatif ve anlamlı olması beklenmektedir.

\section{Ampirik Bulgular}

Pesaran, Shin ve Smith (2001) tarafından geliştirilen Gecikmesi Dağıtılmış Otoregresif Sınır Testi yaklaşımında kritik değerler, değişkenlerin düzeyde (I(0)) veya birinci mertebeden durağan olduğu (I(1)) varsayımında hesaplanmaktadır. Modelde kullanılan değişkenlerin içerisinde ikinci mertebeden durağan (I(2)) değişken olması durumunda, Sınır Testinde hesaplanan F test istatistiğinin doğru sonuçlar vermeyeceği ileri sürülmüştür (Quattara ,2004). Modeldeki değişkenlerin ikinci mertebeden durağan olması (I(2)) ihtimaline karşın değişkenlerin durağanlık sınamaları Genişletilmiş Dickey-Fuller (ADF) ve Philips-Perron (PP) birim kök testleri kullanılarak gerçekleştirilmekte ve durağanlık sınaması sonuçları Tablo 2'de sunulmaktadır. Tablo 2'ye göre modelde kullanılan tüm değişkenler düzeyde $(I(0))$ veya birinci mertebeden durağan (I(1))'dır. 
Tablo 2. Durağanlık Sınaması Sonuçları

\begin{tabular}{|l|c|c|c|c|c|c|c|c|}
\hline \multirow{2}{*}{ Değişkenler } & \multicolumn{4}{|c|}{ ADF } & \multicolumn{4}{c|}{ PP } \\
\cline { 2 - 9 } & \multicolumn{2}{|c|}{ Sabit } & \multicolumn{2}{|c|}{ Sabit ve Trend } & \multicolumn{2}{c|}{ Sabit } & \multicolumn{2}{c|}{ Sabit ve Trend } \\
\cline { 2 - 9 } & $\begin{array}{c}\text { Test } \\
\text { İstatistiği }\end{array}$ & $\begin{array}{c}\text { p- } \\
\text { değeri }\end{array}$ & $\begin{array}{c}\text { Test } \\
\text { İstatistiği }\end{array}$ & $\begin{array}{c}\text { p- } \\
\text { değeri }\end{array}$ & $\begin{array}{c}\text { Test } \\
\text { İstatistiği }\end{array}$ & $\begin{array}{c}\text { p- } \\
\text { değeri }\end{array}$ & $\begin{array}{c}\text { Test } \\
\text { İstatistiği }\end{array}$ & $\begin{array}{c}\text { p- } \\
\text { değeri }\end{array}$ \\
\hline sanayi & -0.03 & 0.95 & -2.66 & 0.26 & -2.16 & 0.22 & -8.34 & 0.00 \\
\hline elektüketim & -0.48 & 0.89 & -1.95 & 0.63 & -4.37 & 0.00 & -7.62 & 0.00 \\
\hline beyazesya & -0.47 & 0.89 & -1.88 & 0.66 & -3.70 & 0.01 & -7.99 & 0.00 \\
\hline KKO & -3.99 & 0.00 & -4.06 & 0.00 & -3.63 & 0.01 & -3.70 & 0.03 \\
\hline$\Delta$ sanayi & -4.85 & 0.00 & -4.83 & 0.00 & -56.35 & 0.00 & -72.45 & 0.00 \\
\hline$\Delta$ elektüketim & -5.31 & 0.00 & -5.27 & 0.00 & -4.37 & 0.00 & -7.62 & 0.00 \\
\hline$\Delta$ beyazesya & -11.35 & 0.00 & -11.30 & 0.00 & -50.49 & 0.00 & -49.37 & 0.00 \\
\hline$\Delta$ kko & -9.88 & 0.00 & -9.85 & 0.00 & -9.68 & 0.00 & -9.64 & 0.00 \\
\hline
\end{tabular}

Not: ADF ve PP testleri için kritik değerler $\% 1, \% 5$ ve $\% 10$ anlam düzeyinde sırasıyla sabit için $-3.47,-2.88$, -2.58 , sabit ve trend için- $4.02,-3.44$ ve -3.14 'tür.

Tablo 2'de yer alan sonuçlara göre, bağımlı değişken birinci mertebeden ve bağımsız değişkenler ise düzeyde veya birinci mertebeden durağandır. Dolayısıyla, sanayi üretim endeksinin bağımsız değişkenlerle ilişkisi Gecikmesi Dağıtılmış Otoregresif Sınır Testi yaklaşımı ile incelenebilecektir.

ARDL modeli seçiminde ve gecikme uzunluğunun belirlenmesinde Akaike (AIC) ve Schwarz (SC) bilgi kriterine göre seçim yapılmıştır. Bu aşamada değişkenler farklı gecikme kombinasyonları ile sınanarak, minimum AIC ve minimum SC değerlerini veren model uygun model olarak alınmıştır. Bu çalışmada optimal gecikme uzunluğu, 3 olarak tespit edilmiştir. Seçilen gecikme uzunluğunda, otokorelasyon ve değişen varyans olmamasına dikkat edilmiştir. Bu çerçevede oluşturulan $\operatorname{ARDL}(3,1,3,2)$ modelinde değişkenler arasında uzun dönemli ilişkinin varlığını sınamak için başvurulan ARDL model Sınır Testi sonuçları Tablo 3'te sunulduğu gibidir.

Tablo 3. ARDL Modeli Sınır Testi Sonuçları

\begin{tabular}{|l|c|c|c|c|}
\hline \multirow{2}{*}{ ARDL $(\mathbf{3 , 1 , 3 , 2 )}$ model F-istatistiği: $\mathbf{7 . 8 0 4 7 1 5}(\mathbf{k}=\mathbf{3})$} \\
\hline \multirow{2}{*}{$\begin{array}{l}\text { Anlamlılık } \\
\text { Seviyesi }\end{array}$} & Sınır Testi Kritik Değer $(\mathbf{n = 1 0 0 0 )}$ & \multicolumn{3}{|c|}{ Sınır Testi Kritik Değer $(\mathbf{n}=\mathbf{8 0})$} \\
\cline { 2 - 5 } & Alt Sınır & Üst Sınır & Alt Sınır & Üst Sınır \\
\hline$\% 1$ & 4.29 & 5.61 & 4.568 & 5.96 \\
\hline$\% 5$ & 3.23 & 4.35 & 3.363 & 4.515 \\
\hline$\% 10$ & 2.72 & 3.77 & 2.823 & 3.885 \\
\hline
\end{tabular}


Sınır Testi için $\mathrm{F}$ istatistiğinin ( $\mathrm{F}$ test-istatistiği $=7.804715) \%$.1 anlamlılık düzeyinde üst bant değerinden büyük olması değişkenler arasında bir eş bütünleşme ilişkisinin varlığına işaret etmektedir. Buna göre, 2007-2020 döneminde sanayi üretim endeksi ile elektrik tüketimi, beyaz eşya üretimi ve imalat sanayi kapasite kullanım oranı arasında uzun dönemli bir ilişki bulunduğu söylenebilmektedir.

Değişkenler arasında uzun dönemli ilişkinin tespit edildiği $\operatorname{ARDL}(3,1,3,2)$ modelinin tahmin ve tanısal test sonuçları Tablo 4'te yer almaktadır. Buna göre, $\operatorname{ARDL}(3,1,3,2)$ modelinde otokorelasyon (Breusch-Godfrey LM testi) ve değişen varyans (Breusch-Pagan-Godfrey testi) bulunmamaktadır. Modelde hata terimlerinin normal dağıldığı (Jarque-Bera testi) ve modelin fonksiyonel formunda hata olmadığı (Ramsey reset testi) tespit edilmiştir.

Tablo 4. ARDL Model Uzun Dönem Tahminleri

\begin{tabular}{|c|c|c|c|}
\hline \multicolumn{4}{|c|}{$\begin{array}{l}\text { Bağımlı Değişken: LSanayi } \\
\text { Model: ARDL }(3,1,3,2)\end{array}$} \\
\hline Değişkenler & Katsayı & StandartHata & t-istatistiği (p-değeri) \\
\hline Lsanayi $(-1)$ & 0.305406 & 0.056173 & $5.436929(0.0000)^{*}$ \\
\hline Lsanayi $(-2)$ & 0.204525 & 0.064567 & $3.167641(0.0019)^{\star}$ \\
\hline Lsanayi $(-3)$ & 0.208557 & 0.059313 & $3.516232(0.0006)^{*}$ \\
\hline Lelektüketim & 0.592530 & 0.074560 & $7.947030(0.0000)^{*}$ \\
\hline Lelektüketim(-1) & -0.256400 & 0.053617 & $-4.782025(0.0000)^{*}$ \\
\hline Lbeyazesya & 0.246416 & 0.032438 & $7.596415(0.0000)^{*}$ \\
\hline Lbeyazesya $(-1)$ & -0.090489 & 0.042568 & $-2.125757(0.0353)^{\star}$ \\
\hline Lbeyazesya(-2) & -0.043601 & 0.040320 & $-1.081375(0.2814)$ \\
\hline Lbeyazesya $(-3)$ & -0.102867 & 0.034069 & $-3.019385(0.0030)^{*}$ \\
\hline$K K O$ & 0.006190 & 0.001569 & $3.946140(0.0001)^{*}$ \\
\hline$K K O(-1)$ & -0.001475 & 0.002025 & $-0.728053(0.4678)$ \\
\hline$K K O(-2)$ & -0.003428 & 0.001630 & $-2.102615(0.0373)^{\star}$ \\
\hline Gün & 0.016664 & 0.002474 & $6.734826(0.0000)^{\star}$ \\
\hline Kriz & -0.018876 & 0.007426 & $-2.541683(0.0121)^{*}$ \\
\hline M1 & -0.159238 & 0.015725 & $-10.12619(0.0000)^{*}$ \\
\hline M2 & -0.100608 & 0.015730 & $-6.395774(0.0000)^{*}$ \\
\hline M3 & -0.051717 & 0.015063 & $-3.433450(0.0008)$ \\
\hline M4 & -0.016735 & 0.009535 & $-1.755125(0.0814)^{\star *}$ \\
\hline M5 & -0.021795 & 0.009413 & $-2.315315(0.0220)^{*}$ \\
\hline M6 & -0.037354 & 0.010082 & $-3.705109(0.0003)^{\star}$ \\
\hline M7 & -0.108988 & 0.014518 & $-7.507001(0.0000)^{*}$ \\
\hline
\end{tabular}




\begin{tabular}{|l|c|c|c|}
\hline M8 & -0.132092 & 0.012040 & $-10.97138(0.0000)^{*}$ \\
\hline M10 & 0.026955 & 0.008826 & $3.054158(0.0027)^{\star}$ \\
\hline M12 & 0.040253 & 0.013774 & $2.922469(0.0041)^{\star}$ \\
\hline$C$ & -2.259935 & 0.550498 & $-4.105258(0.0001)^{\star}$ \\
\hline
\end{tabular}

Not: * ve ** \%5 ve \%1 düzeyinde anlamlıdır. Parantez içindekiler olasılık değerleridir.

$R^{2}: 0.990821$ ve Düzeltilmiş- $R^{2}: 0.989248$; F-istatistiği: 629.6956 (0.0000)

Breusch-Godfrey LM: 10.80571 (0.5456)

Breusch-Pagan-Godfrey: 29.67262 (0.1958)

Jarque-Bera: 2.509343 (0.285169)

Ramsey Reset: 2.635647 (0.1068)

$\operatorname{ARDL}(3,1,3,2)$ uzun dönem modelinden hareketle belirlenen uzun dönem katsayıları Tablo 5'te verilmektedir. Değişkenlerin işareti beklentiye uygun olarak pozitiftir. Elektrik tüketimi ve imalat sanayi kapasite kullanım oranı değişkenleri istatistiksel olarak sanayi üretim endeksini açıklamada anlamlı bulunmuştur. Sanayi üretim endeksini açıklamada uzun dönemde en etkili olan öncül değişken elektrik tüketimidir. Bulunan sonuca göre uzun dönemde, elektrik tüketimindeki \%1'lik artış sanayi üretim endeksini \%1.2 artırmaktadır. Kapasite kullanım oranındaki 1 birimlik değişim ise sanayi üretim endeksini \%0.5 artırmaktadır.

Tablo 5. ARDL Model Uzun Dönem Katsayıları

\begin{tabular}{|l|c|c|c|}
\hline Değişkenler & Katsayı & $\begin{array}{c}\text { Standart } \\
\text { Hata }\end{array}$ & t-istatistiği (p-değeri) \\
\hline Lelektüketim & 1.194018 & 0.175912 & $6.787578(0.0000)^{\star}$ \\
\hline Lbeyazesya & 0.033599 & 0.137299 & $0.244714(0.8070)$ \\
\hline KKO & 0.004575 & 0.002294 & $1.994646(0.0480)^{\star \star}$ \\
\hline
\end{tabular}

Not: * ve ** \%5 ve \%1 düzeyinde anlamlıdır. Parantez içindekiler olasılık değerleridir.

Uzun dönemde parametre kararlılığını incelemek üzere Şekil 2'de yer alan CUSUM ve CUSUMQ grafiklerinden yararlanılmaktadır. Grafikler, uzun dönem ARDL modelinden elde edilen uzun dönem katsayılarının kararlı olduğunu ortaya koymaktadir. 
Şekil 2: CUSUM ve CUSUMQ Grafikleri

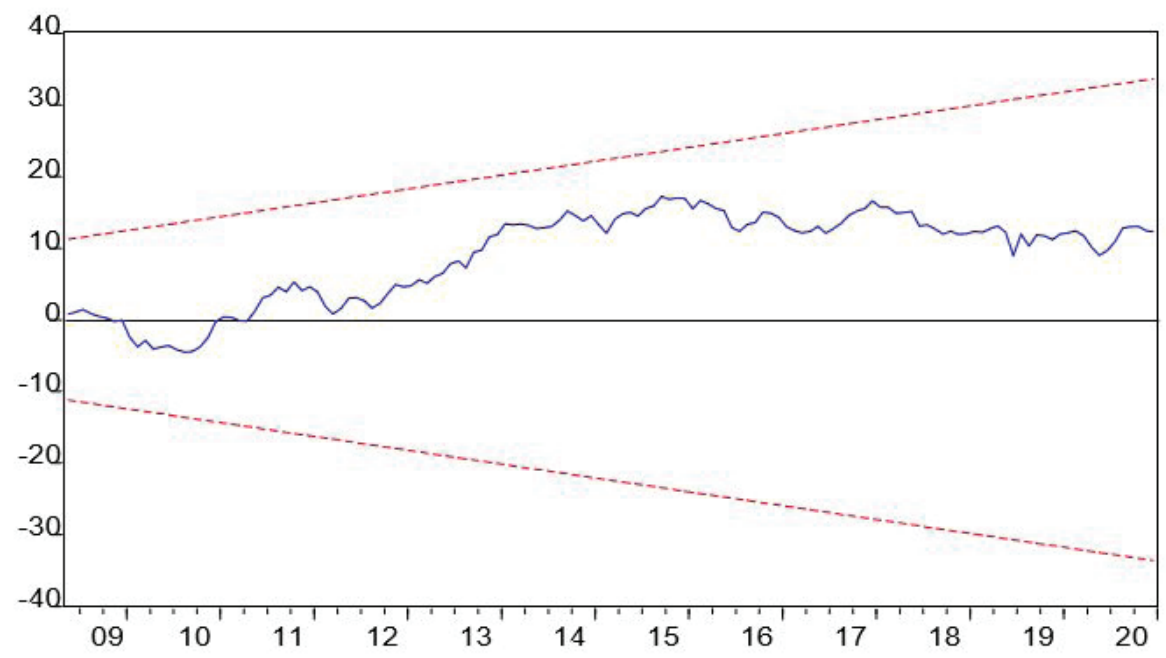

CUSUM__ $5 \%$ Significance

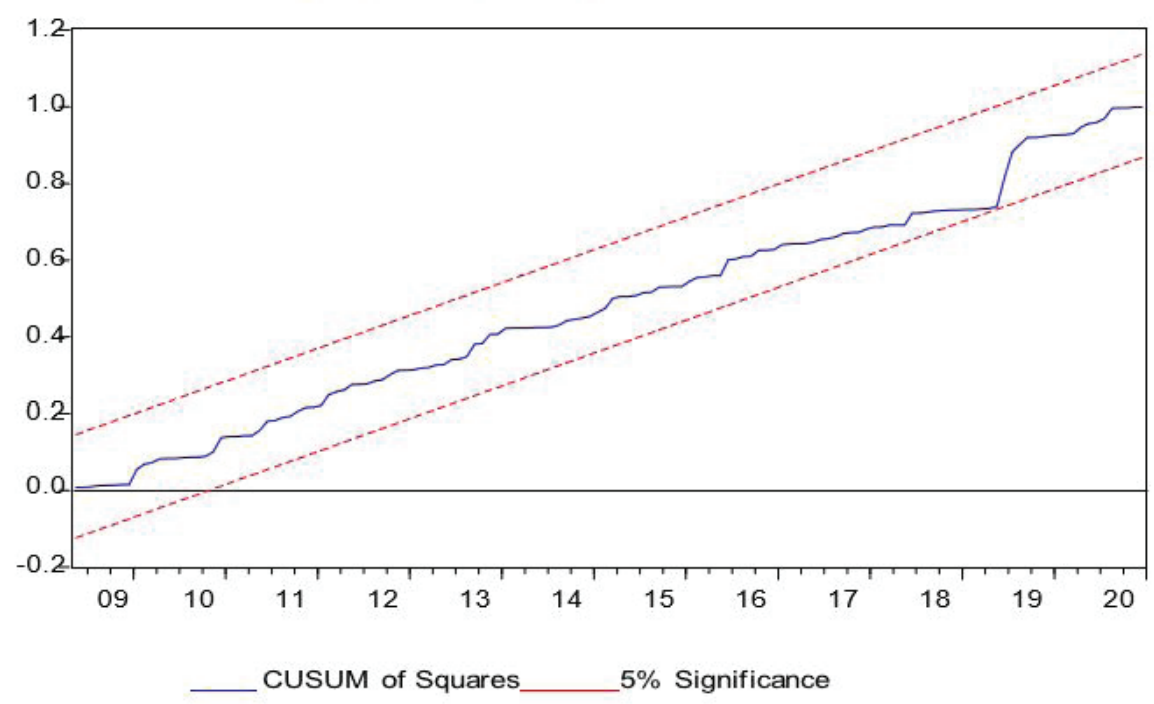

Uzun dönem ARDL model tahmininden hareketle belirlenmiş olan kısa dönem ARDL modeli bulguları Tablo 6'da sunulmaktadır. Kısa dönemde, elektrik tüketiminde meydana gelen \%1'lik artışın sanayi üretim endeksini \%0.6 artırdığı ve beyaz eşya üretiminde meydana gelen \% 1 'lik artışın ise sanayi üretim endeksini \%0.3 arttırdığı sonucuna ulaşıımıştır. Ayrıca, kapasite kullanım oranındaki 1 birimlik 
değişim sanayi üretim endeksini \%0.6 artırmaktadır. Hata düzeltme katsayısının kısa dönem modelinde anlamlı ve negatif çıkması ise uzun dönem dengesinden bir sapma olması halinde sistemin tekrar dengeye geleceğine işaret etmektedir. Buna göre, hata düzeltme katsayısının -0.28 olması, sanayi üretim endeksinde kısa dönemde yaşanan bir şokun etkisiyle uzun dönem dengesinden bir sapma olması halinde sistemin yaklaşık 3.5 aylık dönemde dengeye geleceğini göstermektedir. Başka bir ifadeyle, kısa dönemde yaşanan bir şokun etkisiyle uzun dönem dengesinde meydana gelecek sapmanın 1 aylık dönem sonunda \%28.2'sinin giderilebileceğini göstermektedir.

Kısa dönemde sanayi üretim endeksi üzerinde etkili olan beyaz eşya üretiminin etkisi ise uzun dönemde kaybolmuştur. Ayrıca kapasite kullanım oranının hem uzun hem de kısa dönemde etkisi çok sınırlıdır.

Tablo 6. ARDL Model Kısa Dönem Tahminleri

\begin{tabular}{|c|c|c|c|}
\hline \multicolumn{4}{|c|}{$\begin{array}{l}\text { Bağımlı Değişken: } \Delta \text { (LSanayi) } \\
\text { Model: ARDL }(3,1,3,2)\end{array}$} \\
\hline Değişkenler & Katsayı & Standart Hata & t-istatistiği (p-değeri) \\
\hline$\Delta$ (Lsanayi $(-1))$ & -0.413082 & 0.063924 & $-6.462041(0.0000)^{*}$ \\
\hline$\Delta$ (Lsanayi(-2)) & -0.208557 & 0.058268 & $-3.579264(0.0005)^{*}$ \\
\hline$\Delta$ (Lelektüketim) & 0.592530 & 0.066189 & $8.952060(0.0000)^{*}$ \\
\hline$\Delta$ (Lbeyazesya) & 0.246416 & 0.027727 & $8.887208(0.0000)^{\star}$ \\
\hline$\Delta$ (Lbeyazesya(-1)) & 0.146468 & 0.034711 & $4.219624(0.0000)^{*}$ \\
\hline$\Delta$ (Lbeyazesya(-2)) & 0.102867 & 0.032770 & $3.139090(0.0021)^{*}$ \\
\hline$\Delta(K K O)$ & 0.006190 & 0.001474 & $4.198972(0.0000)^{*}$ \\
\hline$\Delta(K K O(-1))$ & 0.003428 & 0.001523 & $2.249778(0.026)^{\star}$ \\
\hline Gün & 0.016664 & 0.002394 & $6.961228(0.0000)^{*}$ \\
\hline Kriz & -0.018876 & 0.006057 & $-3.116456(0.0022)^{*}$ \\
\hline M1 & -0.159238 & 0.012972 & $-12.27552(0.0000)^{\star}$ \\
\hline M2 & -0.100608 & 0.014034 & $-7.168650(0.0000)^{\star}$ \\
\hline M3 & -0.051717 & 0.014182 & $-3.646761(0.0004)^{*}$ \\
\hline M4 & -0.016735 & 0.008714 & $-1.920553(0.0568)^{\star}$ \\
\hline M5 & -0.021795 & 0.008981 & $-2.426847(0.0165)^{*}$ \\
\hline M6 & -0.037354 & 0.009497 & $-3.933253(0.0001)^{\star}$ \\
\hline M7 & -0.108988 & 0.012952 & $-8.414616(0.0000)^{*}$ \\
\hline M8 & -0.132092 & 0.010614 & $-12.44539(0.0000)^{*}$ \\
\hline M10 & 0.026955 & 0.008597 & $3.135203(0.0021)^{\star}$ \\
\hline M12 & 0.040253 & 0.012756 & $3.155646(0.002)^{*}$ \\
\hline$E C M(-1)$ & -0.281512 & 0.049852 & $-5.646931(0.0000)^{*}$ \\
\hline C & -2.259935 & 0.408349 & $-5.534318(0.0000)^{*}$ \\
\hline
\end{tabular}




\section{Sonuç}

Türkiye ekonomisinde 2007-2020 yılları arasındaki aylık veriler kullanılarak yapılan çalışmada elektrik tüketimi, beyaz eşya üretimi ve imalat sanayi kapasite kullanım oranı değişkenlerinin sanayi üretim endeksine olan etkisi incelenmiştir. Birim kök testi sonuçlarına göre değişkenler farklı mertebeden durağan olduklarından ARDL (Gecikmesi Dağıtılmış Otoregresif) Modeli kullanılarak uzun ve kısa döneme ilişkin tahminler gerçekleştirilmiştir. Uzun dönemde sanayi üretim endeksini açıllamak üzere modelde yer alan elektrik tüketimi, beyaz eşya üretimi ve imalat sanayi kapasite kullanım oranı değişkenlerinin işareti beklentiye paralel olarak pozitiftir ve elektrik tüketimi ile imalat sanayi kapasite kullanım oranı değişkenleri istatistiksel olarak anlamlı bulunmuştur. Sanayi üretim endeksini açıklamada uzun dönemde en etkili olan değişken elektrik tüketimidir. Bulunan sonuca göre uzun dönemde, elektrik tüketimindeki \%1'lik artış sanayi üretim endeksini \%1.2 artıracaktır. Beyaz eşya üretimi ise uzun dönemde istatistiki olarak anlamlı bulunmamıştır. Kısa dönemde ise, modelde yer alan elektrik tüketimi, beyaz eşya üretimi ve imalat sanayi kapasite kullanım oranı değişkenlerinin işareti beklentiye paralel olarak pozitiftir ve istatistiksel olarak anlamlı bulunmuşlardır. Buna göre, kısa dönemde sanayi üretim endeksi üzerinde etkili olan beyaz eşya üretiminin etkisi uzun dönemde kaybolmuştur. Ayrıca kapasite kullanım oranının hem uzun hem de kısa dönemde etkisi çok sınırlıdır. Kısa dönemde modelde kullanılan hata düzeltme katsayısının -0.28 olması, sanayi üretim endeksinde uzun dönem denge değerinden bir sapma olması halinde yaklaşık 3.5 aylık dönemde sistemin dengeye geleceğini göstermektedir. Bu tespitin sanayi üretim endeksine ilişkin oluşturulacak politikalarda göz önünde bulundurulmasının faydalı olacağı düşünülmektedir.

Çalışma sonucuna göre, sanayi üretim endeksini açıklamada hem uzun hem de kısa dönemde etkili olduğu tespit edilen değişken elektrik tüketimidir. Bu bulgu, literatürde elektrik tüketiminin sanayi üretim endeksini açıklamada etkili olduğunu bulan çalışmanın sonuçlarıyla örtüşmektedir (Marchetti ve Parigi, 1998). Ayrıca çalışmadaki bulgular ışı̆̆ında Türkiye'de sanayi üretim endeksinin tahmini için yapılacak çalışmalarda kısa ve uzun dönemde elektrik tüketiminin dikkate alınması anlamlı görünmektedir. 
Bundan sonraki çalışmalarda, sanayi üretim endeksinin ihracat, ara malı ve sermaye malı ithalat, imalat sanayi satın alma yöneticileri endeksi (imalat PMI), otomobil üretimi gibi öncül göstergeleri ile olan ilişkisi araşsırılabilir.

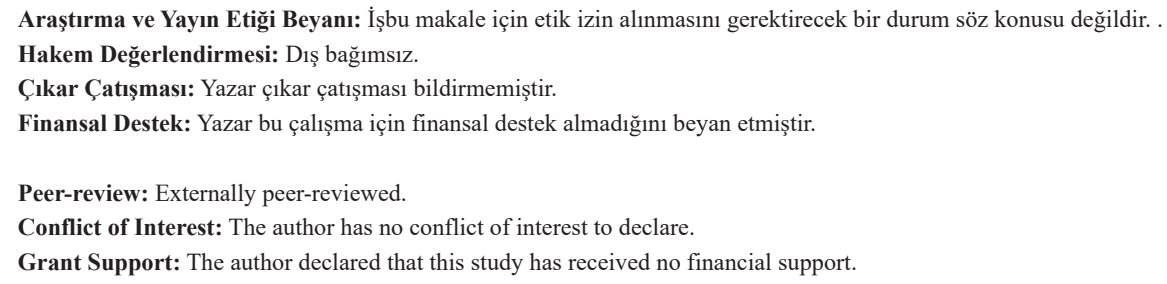

\section{Kaynaklar/References}

Atabek, A., Atuk O., Coşar, E.E. ve Sarıkaya, Ç. (2009). Mevsimsel modellerde çalışma günü değişkeni. TCMB Ekonomi Notları, Sayı: 2009-3.

Barışık, S. ve Yayar, R. (2012). Sanayi üretim endeksini etkileyen faktörlerin ekonometrik analizi. iktisat, Işletme ve Finans, 27 (316), 53-70.

Bayar, G. ve Tokpunar, S. (2014). Türkiye imalat sanayi alt sektörleri üretiminin belirleyicileri- panel veri analizi. Business and Economics Research Journal, 5 (1), 67-85.

Bruno, G. ve Lupi, C. (2003). Forecasting industrial production and the early detection of turning points. The Economics and Statistics Discussion Paper, No. 4/03.

Bruno, G. ve Lupi, C. (2003). Forecasting euro-area industrial production using (mostly) business surveys data. ISAE Istituto di Studi e Analisi Economica.

Çekim Öncel, H. (2018). Examination of industry production index in turkey with time series method. BAUN Fen Bil. Enst. Dergisi, 20 (1), 547-554.

Eğilmez, M. (2014, 15 Haziran). Sanayi üretim endeksini okuma dersi. Kendime yazılar. Erişim adresi: https://www.mahfiegilmez.com/2014/11/sanayi-uretim-endeksi-okuma-dersi.html.

Ejaz, M. Ve lqbal J. (2019). Estimation and forecasting of industrial production index. State Bank of Pakistan. SBP Working Series Paper, No: 103.

Engle, R.F. ve Granger, C.W.J. (1987). Cointegration and error correction: representation, estimation and testing. Econometrica, 55, 251-276.

Erkişi, K. ve Tekin, Ü.E. (2019). The relationship between intermediate and capital goods imports, industrial production and economic growth: the case of Turkey. Journal of Yasar University, $14 / 55,358-368$.

Johansen, S. (1988). Statistical analysis of cointegration vectors. Journal of Economics Dynamic and Control, 12 (2-3), 231-254.

Kaldor, N. (1966). Causes of the slow rate of economic growth of The United Kingdom. Cambridge, Cambridge University Press. 
Kızılca, Zeynep. (2007). Türkiye'de sanayi üretim endeksini etkileyen faktörler ve zaman serisi analizi. (Yüksek Lisans Tezi). İstanbul Üniversitesi Sosyal Bilimler Fakültesi, İstanbul.

Marchetti, D.J. ve Parigi, G. (1998). Energy consumption, survey data and the prediction of industrial production in Italy. Banca D'Italia. Temi Di Discussione. No: 342.

Parigi, G., Golinelli, R. ve Bodo, G. (2000). Forecasting industrial production in the Euro Area. Banca D'Italia. Temi Di Discussione Del Servizio Studi.

Pesaran, M.H., Shin, Y. ve Smith, R.J. (2001). Bounds testing approaches to the analysis of level relationships. Journal of Applied Econometrics, 16(3), 289-326.

Öcal, F. M. (2013). Türkiye'de sanayi üretim endeksi ve imalat sanayi eğilim göstergeleri arasındaki ilişkinin ekonometrik analizi. Celal Bayar Üniversitesi Sosyal Bilimler Dergisi, 11(2), 242-258.

Özturk, M. ve Ağan, Y. (2017). Determinants of industrial production in Turkey. Journal of Economics and Financial Analysis, 1(2), 1-16. http://dx.doi.org/10.1991/jefa.v1i2.a6

Quattara, B. (2004). Foreign aid and fiscal policy in Senegal, Mimeo University of Manchester, 262267. 